\title{
Kultura animacji jako humanistyczna pedagogia
}

\begin{abstract}
Abstrakt
Celem niniejszego opracowania jest próba określenia cech uniwersalnej kultury animacji w ogólności, postrzeganej jako swoista humanistyczna pedagogia w szerokim rozumieniu. Punktem wyjścia autor czyni tu cechy konstytutywne animacji kultury odnoszące się do: (1) rozumienia animacji jako ożywiania, aktywizowania, zmieniania etc.; (2) traktowania kultury własnej jednostek i wspólnot jako zasadniczego przedmiotu jej oddziaływań; (3) realizowania wszelkich działań animacyjnych w oparciu o zasady humanistycznej metodyczności; (4) przyjęcia minimum aksjologiczności jako niezbędnego warunku postrzegania animacji kultury jako idei pedagogicznej oraz (5) sprecyzowania swoistości roli społecznej animatora kultury. W tekście podejmuję próbę ich uogólnienia $\mathrm{z}$ myślą o rozwinięciu pedagogicznej teorii działalności animacyjnej poza jej aspekty - wyłącznie - kulturalne.
\end{abstract}

Słowa kluczowe: animacja kultury, animacja społeczna, pedagogia humanistyczna, zmiana społeczna, metodyka pracy animatora.

\section{Cultural Animation as Humanistic Pedagogy}

\begin{abstract}
The aim of this paper is to determine the characteristics of universal culture of animation in general, seen as a kind of humanistic pedagogy in the broad sense. The starting point for the author are the constitutive features of cultural animation relating to: (1) understanding animation as revival, activation, change etc.; (2) treating the culture of individuals and communities as a key subject of its impact; (3) implementation of any animation activities based on the humanistic methodical principles; (4) adoption of axiological minimum as a necessary condition for the perception of cultural animation as pedagogical idea, and (5) clarifying the specificity of the role of social culture animator. The text attempts to generalize them with a view to developing a pedagogical theory of animation activity beyond its cultural exclusively - aspects.
\end{abstract}

Keywords: cultural animation, social animation, humanistic pedagogy, social change, methods of animator's work.

\footnotetext{
*Uniwersytet Szczeciński, Wydział Humanistyczny, Instytut Pedagogiki.
} 


\section{Wstęp}

Idea animacji społeczno-kulturalnej zrodziła się i wydatnie rozwinęła - zarówno na gruncie teoretycznym, jak i w praktyce - we Francji. Szczyt zainteresowań naukowych tą ideą humanistyczną przypadł w tym kraju na lata 70. i 80. XX w. (m.in. Limbos 1977; Besnard 1980, 1986; Maccio 1983).

Do Polski wiedza o niej docierała wybiórczo za sprawą nielicznych artykułów przeglądowych (m.in. Czerniawska 1974, 1984; Mioduszewska 1979; Bielas 1980; Żebrowski 1981; Dąbrowska 1986) i przekładów pojedynczych tekstów oryginalnych (m.in. Besnard 1988; Poujol 1988). Dopiero ukazanie się w druku dwóch pedagogicznych monografii autorstwa - Jana Żebrowskiego (1987) i Małgorzaty Kopczyńskiej (1993) - w całości poświęconych francuskim doświadczeniom i koncepcjom animacji społeczno-kulturalnej oraz animatora kultury wpłynęło na zasadniczy przełom w recepcji wykładni francuskich i następnie intensywnego rozwoju studiów teoretycznych i badań empirycznych nad animacją społeczno-kulturalną/kulturalną/społeczną w naszym kraju. Moment ten zbiegł się z przełomem transformacyjnym, jaki dokonał się w Polsce po roku 1989, co znalazło odzwierciedlenie w zasadniczej zmianie ustrojowej także w sferze kultury. Idea animacji stała się na tyle nośna, że bardzo szybko została systemowo i spontanicznie rozpowszechniona zarówno w praktyce działalności instytucjonalnej i pozainstytucjonalnej, jak również pojawiła się na uniwersytetach w nazwach specjalności studiów wyższych, a potem osobnych kierunków kształcenia akademickiego, a także w nazwach jednostek naukowych, tytułach wielu konferencji czy publikacji. Wraz ze wzrostem zainteresowania działalnością animacyjną, zasadniczo zaawansowano także studia teoretyczne i badania empiryczne w zakresie tej problematyki, co skutkowało opublikowaniem wielu opracowań naukowych na ten temat ${ }^{1}$.

Animacji kultury/kulturalnej jako idei pedagogicznej poświęciłem kilka swoich projektów badawczych i tekstów naukowych (Kubinowski 1993, 1997, 2000, 2001, 2002, 2013, 2014, 2015). Upowszechnienie animacji społeczno-kulturalnej w Polsce doprowadziło do uniwersalizacji idei animacji jako swoistej pedagogii, między innymi w działalności artystycznej, edukacyjnej, naukowej, religijnej, rehabilitacyjnej, terapeutycznej, rekreacyjnej, turystycznej, prozdrowotnej, gospodarczej, administracyjnej, medialnej, politycznej. Analogicznie upowszechnił się i zuniwersalizował termin „animator” jako potoczne określenie osoby pełniącej określoną rolę społeczną, funkcję zawodową czy ściśle określone zadanie w pracy z ludźmi. Celem niniejszego opracowania jest próba określenia cech uniwersalnej kultury animacji w ogólności, postrzeganej jako swoista humanistyczna pedagogia

\footnotetext{
${ }^{1}$ M.in.: Kargul 1993, 1996, 2012; Gajda (red.) 1993, 1994; Jedlewska 1999; Hrycyk (red.) 2000, 2004; Gajda, Żardecki (red.) 2001; Godlewski, Kurz, Mencwel, Wójtowski (red.) 2002; Żebrowski (red.) 2003; Mendel (red.) 2004, 2005; Jedlewska (red.) 2006; Zierkiewicz, Wnuk (red.) 2006; Červinková (red.) 2008; Kurz (red.) 2008; Matyjewicz 2010; Kubinowski, Lewartowicz (red.) 2013; Delecka-Bury 2015.
} 
w szerokim rozumieniu. Punktem wyjścia czynię tu zaproponowane przeze mnie cechy konstytutywne animacji kultury, odnoszące się do: (1) rozumienia animacji jako ożywiania, aktywizowania, zmieniania etc.; (2) traktowania kultury własnej jednostek i wspólnot jako zasadniczego przedmiotu jej oddziaływań; (3) realizowania wszelkich działań animacyjnych w oparciu o zasady humanistycznej metodyczności; (4) przyjęcia minimum aksjologiczności jako niezbędnego warunku postrzegania animacji kultury jako idei pedagogicznej oraz (5) sprecyzowania swoistości roli społecznej animatora kultury (Kubinowski 2015). W tekście podejmuję próbę ich uogólnienia z myślą o rozwinięciu pedagogicznej teorii działalności animacyjnej poza jej aspekty - wyłącznie - kulturalne.

\section{Ożywianie, aktywizowanie, zmienianie...}

Animacja oznacza przede wszystkim ożywianie, pobudzanie, przywracanie do aktywnego funkcjonowania, rewitalizowanie, inicjowanie, inspirowanie i nadawanie impulsów rozwojowych, ale także stymulowanie zaangażowania jednostkowego i wspólnotowego. Celem zabiegów animacyjnych jest aktywność ludzi, aktywizowanie środowisk społecznych mało zaangażowanych, mobilizowanie instytucji i organizacji do podejmowania i realizowania nowych projektów, zachęcanie pojedynczych osób do zintensyfikowania własnego - czynnego i twórczego uczestnictwa w życiu, przyczynianie się do poprawy warunków sprzyjających efektywności tych wszystkich działań.

Modelowa sytuacja animacyjna w tym wypadku polega na odnalezieniu jednostek, grup czy środowisk mało zaangażowanych, często o nieuświadomionych potrzebach i własnych potencjałach ich zaspokojenia, czasami jako rezultatu pozbawienia ich odpowiednio ukierunkowanych oddziaływań i braku w ich otoczeniu regularnej działalności instytucjonalnej. W takiej sytuacji wyzwaniem animatora staje się przyczynienie za pomocą odpowiednich zabiegów animacyjnych, często wymagających realizacji w dłuższej perspektywie czasowej, do konstruktywnej humanistycznie zmiany w życiu tych jednostek, grup czy środowisk, polegającej na ożywieniu ich egzystencji, wyzwoleniu oddolnych inicjatyw i pojawieniu się konkretnych przejawów uczestnictwa, twórczości, zaangażowania etc. Zmiana tego typu nie może być tylko chwilowym dokonaniem, wymaga utrwalenia poprzez uruchomienie mechanizmów rozpoczętego procesu odchodzenia od marazmu i przechodzenia do względnie ustabilizowanego stanu permanentnej aktywności z pierwszoplanowym udziałem animowanych jednostek, grup i środowisk. $O$ ile stan taki uda się animatorowi osiągnąć, może on podejmować kolejne decyzje dotyczące jego animacyjnego zaangażowania $\mathrm{w}$ dalsze podnoszenie poziomu i jakości owej aktywności bądź może uznać swoje zadanie za wypełnione w konkretnym miejscu i czasie. 


\section{Odkrywanie potencjalności i wspomaganie jej rozwoju}

Podmiotami animacji, w przedstawianym tu rozumieniu, są pojedyncze jednostki ludzkie i wspólnoty społeczne. Jej celem staje się odkrywanie potencjalności konkretnej jednostki lub wspólnoty oraz wspomaganie jej rozwoju. W odniesieniu do jednostek ludzkich potencjalność oznacza ich predyspozycje, uzdolnienia, zainteresowania, potrzeby, preferencje, artykułowane marzenia, plany życiowe, możliwości rozwojowe, ukryte zalążki przyszłej aktywności etc., natomiast w odniesieniu do wspólnot oznacza ona ich własne tradycje, osoby znaczące $\mathrm{z}$ ich środowiska, wspólnotowe zasoby materialne i duchowe, inicjatywy podjęte i zaniechane, możliwości rozwojowe, źródła tożsamości, kapitał ludzki i szanse jego rozwoju, pomysły, idee, perspektywy etc. Wspólnoty to grupy czy środowiska społeczne złożone z osób o podobnych cechach etnicznych, religijnych, zawodowych, demograficznych, fizycznych etc., o zbliżonych zainteresowaniach, pasjach, poglądach, preferencjach etc., skupione wokół jakiejś idei, systemu wartości, światopoglądu, wyzwania etc., mieszkające w jednym lub różnych miejscach, ale utrzymujące ze sobą ścisły kontakt, bezpośredni bądź pośredni za pomocą różnego rodzaju komunikatorów.

W animacji jako idei pedagogicznej nie chodzi o nakłanianie ludzi do praktykowania innej niż ich własna potencjalności, choć oczywiście potencjalność poszczególnych jednostek i wspólnot mogą ewoluować pod wpływem różnych oddziaływań. Wartością nadrzędną jest w niej potencjalność własna - jej uświadomienie, odkrywanie, przeżywanie osobiste, rozwijanie, promowanie, przekazywanie, obrona etc. Animator $\mathrm{w}$ tym wypadku staje przed wyzwaniem tolerancji i szacunku wobec potencjalności wszystkich ludzi i wszelkich grup społecznych, a jego zadaniem jest jej poznanie i rozumienie oraz dodawanie sił jej nosicielom w jej pozytywnej waloryzacji, jej twórczym pielęgnowaniu oraz zachęcanie do podejmowania aktów twórczych opartych na własnych wartościach i mobilizowanie do dbania o ich godną obecność i rozwój zarówno we własnym życiu, jak i w obiegu społecznym.

\section{Humanistyczna metodyczność i kształcenie człowieka}

Cechą konstytutywną animacji jako idei pedagogicznej jest jej humanistyczna metodyczność. Chodzi o stosowanie wyłącznie zabiegów animacyjnych odpowiadających metodyce niedyrektywnej, podmiotowej, zindywidualizowanej, zawsze dopasowanej do kontekstu społecznego i osobowego, emergentnej o formule otwartej, czyli dalekiej od schematycznych, mechanistycznych, standardowych, normalizowanych etc. rozwiązań, a bliskiej podejściom elastycznym, empatycznym, kreatywnym, adekwatnym etc. 
Jednocześnie niedopuszczalne jest tu wykorzystywanie przymusu czy presji, a także jakichkolwiek przejawów manipulacji oraz sztucznych zachęt, w tym między innymi rekompensat materialnych czy prestiżowych. 0 ile dana jednostka czy wspólnota nie chce się angażować w proponowane i realizowane przez innych działania, obowiązkiem animatora - jako zaangażowanego pedagoga humanistycznego - jest uszanowanie takich postaw, niezależnie od możliwego ich oddziaływania na innych. Postawy odmowy zaangażowania nie zawsze muszą przecież wynikać z niechęci, sprzeciwu, krytyki czy zamiaru destrukcji. Jednocześnie sygnalizują one animatorowi pojawienie się kolejnych wyzwań w jego działalności, a czasami także sugerują potrzebę modyfikacji jego postępowania, być może zbyt pospiesznego czy zbyt nachalnego. Idea animacji ulega dehumanizacji w sytuacji, gdy za sprawą nieodpowiedzialnych działań animatora ktoś poczuje się skonfundowany, urażony, pokrzywdzony, skompromitowany, stygmatyzowany, marginalizowany, wykluczony etc. Podmiotowe prawo każdego człowieka do indywidualnego wyboru musi pozostać fundamentem wszelkich przejawów animacji, o ile ma ona pozostać ideą pedagogiczną.

Pytanie o metodykę tak rozumianej animacji może dotyczyć wyłącznie zasad działania, a z całą pewnością nie może odnosić się do oczekiwania na podanie uniwersalnych, ścisłych przepisów postępowania animatora, wyabstrahowanych kontekstualnie. W klasycznej propozycji Henri Thery'ego (por. Kopczyńska 1993: 38) animacja obejmuje trzy zasadnicze procesy: odkrywania potencjałów, inicjowania współpracy między ludźmi i rozwijania twórczości. W ramach każdego z tych procesów stosować będziemy inne zabiegi animacyjne, a różnice te będą się pogłębiały w zależności od dziedziny aktywności, typów uczestników, czasu i miejsca działań, możliwości realizacyjnych etc. Ich wymiar metodyczny będzie odpowiednio dobierany, konstruowany i wdrażany w praktyce zgodnie z przyjętymi założeniami i jako wynik bieżących decyzji podejmowanych przez animatora $\mathrm{w}$ toku realizacji konkretnych działań.

Humanistyczna metodyczność animacji ma prowadzić do kształcenia człowieka świadomego własnych możliwości, zainteresowanego ich aktywnym rozwijaniem, doceniającego wartości wspólnot, w które się angażuje, zmierzającego do realizacji wybranych dróg i projektów życiowych, odpowiedzialnego za konstruktywne formowanie własnej osobowości, rozumiejącego wagę wolności osobistej i mądrze z niej korzystającego, doceniającego znaczenie dobra publicznego i aktywnie włączającego się w jego twórcze pomnażanie wedle własnych preferencji.

\section{Konstruktywny relatywizm i minimum aksjologiczności}

Wobec ogromnego zróżnicowania wartości, wzorów, norm kulturowych (dawnych i obecnych) oraz wynikających z nich zachowań niezbędne jest - moim zdaniem - dodanie do zestawu cech konstytutywnych animacji zasady konstruktywnego 
relatywizmu i minimum aksjologiczności, o ile traktować ją mamy jako ideę pedagogiczną. Chodzi tu o powstrzymywanie się animatorów od bezwzględnego wartościowania konkretnych wytworów czy przejawów ludzkiej aktywności z jednej wyłącznie perspektywy ideologicznej, estetycznej, etycznej etc. i posługiwanie się w nim konstruktywnym relatywizmem aksjologicznym, co wymaga od niego kompetencji w wielu dziedzinach, taktu pedagogicznego, zdolności empatycznych, umiejętności adekwatnego rozumienia i otwartości na Inność. Jednocześnie niezbędne jest w tej formule wartościowania pedagogicznego wprowadzenie i stosowanie w praktyce animacyjnej zasady minimum aksjologiczności, która oznacza, że animator nie może godzić się na bylejakość, powierzchowność czy absurdalność swojej działalności, nie może akceptować zachowań niepożądanych, nie może tym bardziej pozwolić na działania destrukcyjne czy wręcz niszczycielskie.

Minimum aksjologiczności w kulturze animacji jako idei pedagogicznej określa jednoznacznie, że projektowane i realizowane zabiegi animacyjne, wszelkie działania i ich rezultaty, a także postawy, zachowania i nastawienia animatora oraz wszystkich podmiotów jego oddziaływań muszą być konstruktywne humanistycznie, czyli prowadzić do realizacji idei humanizmu, czyli służenia dobru człowieka. Animator jako pedagog nie może w żadnym przypadku legitymizować swoimi działaniami destruktywnych humanistycznie przejawów aktywności. Nie chodzi bowiem o to, żeby „animować dla samego animowania” i satysfakcjonować się jedynie faktem udanej aktywizacji. Chodzi o to, aby animacja przyczyniała się do rozwoju proosobowego i prospołecznego jednostek i wspólnot. Przy tym należy zdawać sobie sprawę, że stosowanie tej zasady w praktyce działalności animacyjnej może często przysparzać wielu trudności w doborze adekwatnych kryteriów aksjologicznych i wiązać się z wystąpieniem nieuniknionych dylematów tak rozumianego wartościowania humanistycznego.

\section{Społeczna rola animatora}

Animator to ściśle określona rola społeczna, którą podejmują i realizują ludzie o różnych zawodach i pełnionych funkcjach. Jest to rola społeczna daleka od zarządzania, kierowania, instruowania, nauczania, instrumentalnego wpływania czy tendencyjnego kształtowania. Najlepszy animator to ten, który ożywia, aktywizuje, zmienia etc. życie jednostek lub wspólnot, jednocześnie nie eksponując siebie i swoich dokonań, pozostając niedostrzegalny w ferworze codziennych działań i oddziaływań. Intencjonalnie pozostaje jakby w tle, z boku, na marginesie głównych wydarzeń, ale jednocześnie jest ich prymarnym sprawcą, choć nie bezpośrednim wykonawcą. Jest też strażnikiem misji animacji nasyconej wartościami humanistycznymi i przesłaniem pedagogicznym. Jak każdy wychowawca towarzyszy i wspiera w razie potrzeby podmioty swoich oddziaływań. Jeśli oni radzą sobie 
świetnie bez niego, przyjmuje pozycję bacznego obserwatora, z troską przyglądającego się animowanym jednostkom i wspólnotom. Jeśli jego misja definitywnie się kończy, bo już nie ma czego i kogo ożywiać, aktywizować, zmieniać etc., gdyż cele te zostały w pełni osiągnięte, to czasowo lub na stałe zawiesza swoją współpracę z konkretnymi jednostkami i wspólnotami. Nie jest już po prostu im potrzebny, co nie oznacza, że jego misja i wynikająca z niej rola społeczna umiera. Animator staje wobec kolejnych wyzwań, w nowych okolicznościach, poszukując miejsc i ludzi „uśpionych”, potrzebujących aktywizacji, wymagających ożywienia, poszukujących możliwości zmiany.

Tym samym można uznać, że animator - rozumiany w kategoriach dobrowolnie podejmowanej i pełnionej roli społecznej - staje się bohaterem naszych czasów, choć jednocześnie może wydać się postacią tragiczną. Tragizm animatora, wyrażający się w nieuchronności finału zaangażowanego, efektywnego, satysfakcjonującego działania animacyjnego na continuum od beznadziejnego marazmu do ustabilizowanej aktywności, wyznaczanego autodestruktywną decyzją jego samego, może być jednocześnie postrzegany jako przejaw wyjątkowej pedagogii, w której dobro jednostki i wspólnoty oraz ich rozwój stają się najwyższymi wartościami humanistycznymi.

Termin „kultura” ma swój źródłosłów w języku łacińskim, w którym słowo cultura oznacza uprawę i kształcenie (Kopaliński 1999: 284). Pierwszym w dziejach myślicielem, który użył tego terminu w znaczeniu przenośnym był Cyceron, wprowadzając do literatury filozoficznej określenie cultura animi, które rozumiał jako 'uprawę umysłu'. W ten sposób w starożytności zapoczątkowana została humanistyczna tradycja rozumienia kultury jako szczególnej pedagogii.

Kultura animacji jest jedną z ważniejszych współcześnie humanistycznych pedagogii. Animacja to „uprawianie duchowości” jednostek i wspólnot w szczególny sposób. Taki styl myślenia oraz działania znajduje i może znajdować zastosowanie w różnych sferach naszego życia, przyczyniając się do kształcenia osobowości metodami humanistycznymi. Jest to niezwykle trudna w realizacji metodyka, bo nie posiada prostych rozwiązań, jednoznacznych wskazań, czy gotowych przepisów do uniwersalnego zastosowania. Opiera się na wierze w potencjalność każdej jednostki i wspólnoty, a zmierza do jej odkrywania, rozwijania, aktywizowania, wzbogacania etc. Wszyscy prawdziwi animatorzy zasługują więc na miano zaangażowanych pedagogów humanistycznych. 


\section{Bibliografia}

Besnard P. (1980) L'Animation socio-culturelle, Paris, Presses Universitaires de France.

Besnard P. (1986) Animateur socioculturel : fonctions, formation, profession, Paris, Les Editions ESF.

Besnard P. (1988) Problematyka animacji społeczno-kulturalnej w: Rozprawy o wychowaniu, M. Debesse, G. Mialaret (red.), tłum. Z. Zakrzewska, t. 2, Warszawa, Państwowe Wydawnictwo Naukowe.

Bielas L. (1980) O animacji społeczno-wychowawczej we Francji, „Nowa Szkoła”, nr 11.

Czerniawska 0. (1974) Animacja jako metoda pracy kulturalno-oświatowej i społeczno-wychowawczej, „Oświata Dorosłych”, nr 8.

Czerniawska O. (1984) Animacje społeczno-kulturalne we Francji: geneza i rozwój, „Pedagogika Pracy Kulturalno-Oświatowej”, nr 6.

Červinková H. (red.) (2008) Animatorzy społeczni na rzecz osób niepełnosprawnych. Aktywizacja środowiska na pograniczu, Wrocław, Elwoj Jerzy Wojciechowski.

Dąbrowska E. (1986) Analiza sytuacji animacyjnych, „Pedagogika Pracy Kulturalno-Oświatowej", nr 7.

Delecka-Bury A. (2015) Źródła sukcesu pedagogicznego animatorów kultury muzycznej: studium przypadków, Kraków, Oficyna Wydawnicza „Impuls”.

Gajda J. (red.) (1993) Wybrane problemy animacji kulturalnej, Lublin, Wydawnictwo Uniwersytetu Marii Curie-Skłodowskiej.

Gajda J. (red.) (1994) Animacja kulturalna jako problem pedagogiczny, Lublin, Agencja Dziennikarska VIPress.

Gajda J., Żardecki W. (red.) (2001) Dylematy animacji kulturalnej, Lublin, Wydawnictwo Uniwersytetu Marii Curie-Skłodowskiej.

Godlewski G., Kurz I., Mencwel A., Wójtowski M. (red.) (2002) Animacja kultury - doświadczenie i przyszłość, Warszawa, Instytut Kultury Polskiej UW.

Hrycyk K. (red.) (2000) Animacja społeczno-kulturalna wobec przemian cywilizacyjnych. Animacja - animator i jego kształcenie, Wrocław, „Silesia”.

Hrycyk K. (red.) (2004) Konteksty animacji społeczno-kulturalnej, Wrocław, „Silesia”. 
Jedlewska B. (1999) Animatorzy kultury wobec wyzwań edukacyjnych, Lublin, Wydawnictwo Uniwersytetu Marii Curie-Skłodowskiej.

Jedlewska B. (red.) (2006) Akademickie kształcenie animatorów i menedżerów kultury w Polsce: koncepcje, doświadczenia, wyzwania, Lublin, Oficyna Wydawnicza „Verba”.

Kargul J. (1993) Animacja społeczno-kulturalna w: Pedagogika społeczna. Człowiek $w$ zmieniającym się świecie, T. Pilch, I. Lepalczyk (red.), Warszawa, Wydawnictwo „Żak”.

Kargul J. (1996) Od upowszechniania kultury do animacji kulturalnej, Toruń, Wydawnictwo „Adam Marszałek”.

Kargul J. (2012) Upowszechnianie, animacja, komercjalizacja kultury, Warszawa, Wydawnictwo Naukowe PWN.

Kopaliński W. (1997) Słownik wyrazów obcych i zwrotów obcojęzycznych z almanachem, Warszawa, Muza SA.

Kopczyńska M. (1993) Animacja społeczno-kulturalna: podstawowe pojęcia i zagadnienia, Warszawa, Centrum Animacji Kulturalnej.

Kubinowski D. (1993) Funkcje wiejskich zespołów folklorystycznych w animacji tożsamości kulturowej regionu w: Wybrane problemy animacji kulturalnej, J. Gajda (red.), Lublin, Agencja Dziennikarska VIPress.

Kubinowski D., (1997) Animacja taneczna w: tenże, Proces wychowania tanecznego $w$ środowisku wiejskim, Lublin, Wydawnictwo Uniwersytetu Marii Curie-Skłodowskiej.

Kubinowski D. (2000) Rewitalizacja tradycyjnych wartości we współczesnej kulturze: etnopedagogia wobec globalizacji w: O nowy humanizm $w$ edukacji, J. Gajda (red.), Kraków, Oficyna Wydawnicza „Impuls”.

Kubinowski D. (2001) Zasada konstruktywnego relatywizmu jako podstawa aksjologiczna działalności animacyjnej: perspektywa antropologiczno-pedagogiczna w: Dylematy animacji kulturalnej, J. Gajda, W. Żardecki (red.), Lublin, Wydawnictwo Uniwersytetu Marii Curie-Skłodowskiej.

Kubinowski D. (2002) Od pracy kulturalno-oświatowej do animacji kultury w: tenże, Etnopedagogia taneczna $w$ okresie transformacji. Proces rekonstrukcji rodzimych tradycji tanecznych a współczesne przemiany instytucjonalnej działalności kulturalnej $w$ Polsce, Lublin, Wydawnictwo Uniwersytetu Marii Curie-Skłodowskiej.

Kubinowski D. (2013) Współczesne paradygmaty animacji kultury w: Animacja kultury - współczesne dyskursy teorii i praktyki, D. Kubinowski, U. Lewartowicz (red.), Lublin, Wydawnictwo „Makmed”. 
Kubinowski D. (2014) Animacja kultury jako nowy kierunek akademickiego kształcenia praktycznego w: Kompetencje do prowadzenia edukacji kulturalnej, K. Olbrycht, B. Głyda, A. Matusiak (red.), Katowice, Wydawnictwo Uniwersytetu Śląskiego.

Kubinowski D. (2015) Istota animacji kultury jako idei pedagogicznej, „Studia Kulturowo-Edukacyjne", t. X, nr 1.

Kubinowski D., Lewartowicz U. (red.) (2013) Animacja kultury - współczesne dyskursy teorii i praktyki, Lublin, Wydawnictwo „Makmed”.

Kurz I. (red.) (2008) Lokalnie: animacja kultury = community arts, Warszawa, Instytut Kultury Polskiej UW.

Limbos E. (1977) L'Animation des groupes de culture et de loisirs connaissance du problème, applications pratiques, à l'usage des psychologues, des animateurs et des responsables, Paris, Les Éditions E.S.F.

Maccio Ch. (1983) Animation de groupes, Lyon, Chronique sociale.

Matyjewicz M. (2010) Animacja kulturalna. W poszukiwaniu obszarów współczesnego wychowania, Olsztyn, Zakład Poligraficzny „Spręcograf”.

Mendel M. (red.) (2004) Animacja wspótpracy środowiskowej, Toruń, Wydawnictwo „Adam Marszałek".

Mendel M. (red.) (2005) Animacja współpracy środowiskowej na wsi, Toruń, Wydawnictwo „Adam Marszałek”.

Mioduszewska A. (1979) Kształcenie animatorów kultury we Francji, „Pedagogika Pracy Kulturalno-Oświatowej" nr 4.

Poujol G. (1988) Kształcenie animatorów w: Rozprawy o wychowaniu, M. Debesse, G. Mialaret (red.), tłum. Z. Zakrzewska, t. 2, Warszawa, Państwowe Wydawnictwo Naukowe.

Zierkiewicz E., Wnuk W. (red.) (2006) Tworzyć, zmieniać, aktywizować... Animacja społeczno-kulturalna jako mobilizowanie potencjału indywidualnego i przeciwdziałanie bezradności społecznej, Wrocław, MarMar Marian Kaczorowski.

Żebrowski J. (1981) O animatorach kulturalnych we Francji, „Oświata Dorosłych”, nr 8.

Żebrowski J. (1987) Zawód i osobowość animatorów kultury w świetle nowych koncepcji wychowania zintegrowanego, Gdańsk, Wojewódzki Ośrodek Kultury.

Żebrowski J. (red.) (2003) Animacja kulturalna i społeczno-wychowawcza w środowiskach lokalnych, Gdańsk, Gdańskie Towarzystwo Naukowe. 
Dariusz Kubinowski

\section{Cultural Animation as Humanistic Pedagogy}

The idea of social-cultural animation was born and has considerably grown - both theoretically and in practice - in France. To Poland the knowledge of it has been brought selectively through few review articles and translations of single original texts. Only the publication of two pedagogical monographs (by Jan Żebrowski and Małgorzata Kopczyńska), entirely devoted to the French experiences and concepts of social-cultural animation and culture animator, contributed to a major breakthrough in the reception of the French interpretation and, later, to the intensive development of the theoretical and empirical research on animation and its social-cultural/cultural/social form in our country.

The dissemination of social-cultural animation in Poland has led to the universalization of the idea of animation as a kind of pedagogy, including that within the artistic, educational, scientific, religious, rehabilitative, therapeutic, recreational, tourism-related, health-related, economic, administrative, media, and political activity. Similarly, the term "animator" has become widespread and universal as the colloquial definition of a person holding a certain social role, professional function, or a strictly defined task in working with people.

The starting point here are the constitutive features of cultural animation, proposed by me and relating to: (1) understanding animation as revival, activation, change, etc.; (2) treating the culture of individuals and communities as a key subject of its impact; (3) implementing any animation activities based on the principles of humanistic methodicalness; (4) adopting the minimum of axiology as a necessary condition for the perception of cultural animation as a pedagogical idea; and (5) clarifying the specificity of the social role of a culture animator.

Animation primarily means reviving, stimulating, restoring to active functioning, revitalizing, initiating, inspiring and transmitting impulses for development, but also stimulating the involvement of the individual and community. The aim of animation is people's activity, activating social environments that are little involved, mobilizing institutions and organizations to undertake and implement new projects, encouraging individuals to intensify their own - active and creative - participation, contributing to improving the conditions for the effectiveness of all these operations.

The subjects of animation, in the meaning presented here, are single individuals and social communities. Its aim is to discover the potentiality of a particular individual or a community and support their development. With respect to human beings, potentiality means their abilities, aptitudes, 
interests, needs, preferences, articulated dreams, life plans, growth opportunities, hidden seeds of future activity, etc., while in case of communities it means their own traditions, significant persons from their environment, community resources - material and spiritual, initiatives taken and abandoned, development opportunities, sources of identity, human capital and its development opportunities, ideas, concepts, perspectives, etc.

A constitutive trait of animation as pedagogical idea is its humanistic methodicalness. This refers to the sole use of animation activities corresponding to the non-directive, personal, and individualized methodology always tailored to the social and personal context, with the emergent, open format, which is far from schematic, mechanistic, standardized, normalized, etc. solutions and close to flexible, empathic, creative, adequate, etc. approaches.

The minimum of axiology in cultural animation as pedagogical idea states explicitly that the designed and implemented animation efforts, all actions and their results, as well as behaviors and attitudes of the animator and all the subjects of his/her effects must be humanistically constructive. This means that they need to lead to the realization of the idea of humanism, that is, serving the well-being of man.

The animator - understood in terms of the voluntarily undertaken and performed social role - becomes a hero of our times, but at the same time may seem a tragic figure. The tragedy of the animator, expressed in the inevitability of the final of the engaged, effective, and satisfactory animation activity on a continuum from hopeless apathy to stable activity, which is determined by his/her self-destructive decision, can also be seen as a manifestation of unique pedagogy, in which the good of the individual and the community and their development become the highest humanistic values.

Cultural animation is one of the important contemporary humanistic pedagogies. Animation is "practicing the spirituality" of individuals and communities in a special way. This style of thinking and action is and can be applied in various spheres of our life, contributing to the shaping of personality with humanistic methods. It is a methodology extremely difficult to be implemented, because it does not have simple solutions, clear indications or regulations ready for universal use. It is based on the faith in the potentiality of each individual and community, and strives for their discovery, development, activation, enrichment, etc. All true animators deserve to be referred to as committed humanistic pedagogues.

Translation by Magdalena Machcińska-Szczepaniak 